\title{
Alterations of adiponectin gene expression and DNA methylation in adipose tissues and blood cells are associated with gestational diabetes and neonatal outcome
}

\author{
Raffael Ott' ${ }^{1}$ Jens H. Stupin², Kerstin Melchior' ${ }^{1}$ Karen Schellong' ${ }^{1}$, Thomas Ziska', Joachim W. Dudenhausen²,
} Wolfgang Henrich ${ }^{2}$, Rebecca C. Rancourt ${ }^{*+}$ (i) and Andreas Plagemann ${ }^{1+}$

\begin{abstract}
Background: Adiponectin critically contributes to metabolic homeostasis, especially by insulin-sensitizing action. Gestational diabetes mellitus (GDM) is characterized by insulin resistance leading to materno-fetal hyperglycemia and detrimental birth outcomes. By investigating paired subcutaneous (SAT) and visceral adipose tissue (VAT) as well as blood (cell) samples of GDM-affected $(n=25)$ vs. matched control $(n=30)$ mother-child dyads of the prospective "EaCH" cohort study, we addressed whether alterations of adiponectin plasma, mRNA, and DNA methylation levels are associated with GDM and offspring characteristics.

Results: Hypoadiponectinemia was present in women with GDM, even after adjustment for body mass index (BMI). This was accompanied by significantly decreased mRNA levels in both SAT and VAT $(P<0.05)$, independent of BMI. Maternal plasma adiponectin showed inverse relations with glucose and homeostatic model assessment of insulin resistance (both $P<0.01$ ). In parallel to reduced mRNA expression in GDM, significant $(P<0.05)$ yet small alterations in locus-specific DNA methylation were observed in maternal fat $(\sim 2 \%)$ and blood cells $(\sim 1 \%)$. While newborn adiponectin levels were similar between groups, DNA methylation in GDM offspring was variously altered $(\sim 1-4 \% ; P<0.05)$.

Conclusions: Reduced adiponectin seems to be a pathogenic co-factor in GDM, even independent of BMI, affecting materno-fetal metabolism. While altered maternal DNA methylation patterns appear rather marginally involved, functional, diagnostic, and/or predictive implications of cord blood DNA methylation should be further evaluated.
\end{abstract}

Keywords: Gestational diabetes mellitus, Epigenetics, DNA methylation, Adiponectin, Adipose tissue, Blood cells, Cord blood, Offspring

\section{Background}

Gestational diabetes mellitus (GDM) is one of the most frequent metabolic disorders in pregnancy affecting meanwhile $>10 \%$ of women in Western countries [1-3]. Both increased peripheral insulin resistance and failed

\footnotetext{
*Correspondence: rebecca.rancourt@charite.de

${ }^{\dagger}$ Rebecca C. Rancourt and Andreas Plagemann contributed equally to this work.

'Division of 'Experimental Obstetrics,' Clinic of Obstetrics, Charité Universitätsmedizin Berlin, Corporate Member of Freie Universität Berlin, Humboldt-Universität zu Berlin, and Berlin Institute of Health, Campus Virchow-Klinikum, Augustenburger Platz 1, 13353 Berlin, Germany Full list of author information is available at the end of the article
}

compensation of insulin need are hallmarks of GDM [4]. While causes for these characteristics remain unclear, other endocrine factors are potentially contributing.

Adiponectin $(A D I P O Q)$ is a key hormone in energy metabolism, critically involved in maintaining insulin sensitivity, glucose, and lipid homeostasis [5]. Accordingly, hypoadiponectinemia has been observed in insulin resistance, type 2 diabetes, GDM, and obesity [6, 7]. Interestingly, studies suggest that low adiponectin levels in early pregnancy represent a risk marker for GDM development [8], and the clinical relevance has been debated [9]. Furthermore, hypoadiponectinemia during

(C) The Author(s). 2018 Open Access This article is distributed under the terms of the Creative Commons Attribution 4.0 International License (http://creativecommons.org/licenses/by/4.0/), which permits unrestricted use, distribution, and 
gestation and/or post-partum is associated with poorer maternal insulin sensitivity after delivery and may predict future development of type 2 diabetes $[10,11]$. In a normal pregnancy, maternal circulating adiponectin levels progressively decline particularly in the third trimester along with increasing insulin resistance [12]. Hence, a critical role of adiponectin in gestational metabolic adaptations has been proposed [13]. Adiponectin cannot cross the placenta but is able to influence materno-fetal nutrient transport directly by modulating insulin signaling in syncytiotrophoblast cells [14]. Collectively, adiponectin appears to be not only a specific factor for regulating materno-fetal metabolism but also an important candidate in GDM pathophysiology.

Adipose tissue represents the main source of adiponectin [5]. It has been proposed that production is higher in subcutaneous (SAT) than in visceral adipose tissue (VAT) [15-18]. In GDM, only two studies so far investigated $A D I P O Q$ gene expression and found decreased mRNA levels in adipose tissues [19, 20]. However, both studies were rather limited in sample size, one had only access to SAT biopsies [19], or their group comparisons did not reach statistical significance in SAT and VAT, despite an even significant higher body mass index (BMI) in the GDM group [20]. Thus, it should be further evaluated if $A D I P O Q$ gene expression is indeed altered in patients with GDM, in comparison to BMImatched controls, as differential adiposity states impede the interpretation of a genuine GDM effect. Furthermore, if mRNA levels are affected, causal factors should be explored to gain more insights into the potential mechanisms of GDM.

Regulation of $A D I P O Q$ mRNA expression is complex, and a variety of transcription factors has been identified [21]. Additionally, recent studies suggest a major role of epigenetic mechanisms, namely DNA methylation, in $A D I-$ $P O Q$ transcription [22, 23]. DNA methylation occurs mainly on cytosine-guanine $(\mathrm{CpG})$ dinucleotides. In general, increased methylation is commonly interpreted to be associated with repression of gene transcription; however, underlying mechanisms are more complex and certainly depend on the genomic/genetic location [24]. While patterns of DNA methylation can occur in a tissue-specific manner, they can be similar in other tissues, e.g., circulating blood cells, which would allow easy access for experimental and clinical purposes. Evaluation of potential functional relevance of DNA methylation signatures in the tissue of origin as well as cross-tissue reliability appears critical in this regard. Accordingly, DNA methylation represents a mechanism through which $A D I P O Q$ transcription might be affected, but studies are lacking so far investigating this in adipose tissue from GDM patients.

Offspring of women with GDM are at increased risk for the development of glucose intolerance and associated disturbances later in life $[4,25]$. The main (molecular) causes of this phenomenon remain unclear, but epigenetic mechanisms are increasingly suggested as a functional transmitter. Specifically, early in-life alterations of the DNA methylation pattern might lead to long-term dysregulation of gene expression, e.g., for $A D I P O Q$. Bouchard et al. [22] showed that maternal glucose levels at GDM screening are associated with placental DNA methylation of $A D I P O Q$. This may indicate that materno-fetal (hyper)glycemia is involved in the programming of DNA methylation signatures. The placenta, however, does not appear to represent a key source tissue of adiponectin $[9,14,20]$. Therefore, further cross-tissue studies may provide additional information on whether and where ADIPOQ DNA methylation patterns are altered in the context of hyperglycemic materno-fetal conditions.

In the present study, we therefore analyzed adiponectin plasma levels and gene expression in SAT and VAT biopsies from women with GDM and matched normal glucose tolerant (NGT) controls. Furthermore, we investigated whether DNA methylation is associated with mRNA levels and shows consistency across maternal adipose tissues and blood (MB) cells. Finally, we determined DNA methylation of $A D I P O Q$ in cord blood (CB) cells to evaluate the changes in offspring from GDM mothers and their potential implications.

\section{Results}

\section{Study cohort}

Table 1 shows general and specific characteristics of mothers and newborns. On average, both the GDM and NGT groups were overweight before pregnancy. Total gestational weight gain (GWG) was similar between the groups, while net GWG was significantly lower in diabetic subjects. At delivery, women of both groups showed comparable BMI. In GDM, maternal metabolic and hormonal state was still altered at the end of pregnancy as compared to controls. Fasting blood glucose, insulin, C-peptide, and homeostatic model assessment of insulin resistance (HOMA-IR) were higher in women with GDM. In contrast, plasma adiponectin was significantly lower in the GDM group (Table 1). This was independent of maternal BMI (adjusted for prepregnancy BMI, $P=0.006$; adjusted for BMI at delivery, $P=0.004$ ).

Across the whole cohort $(n=55)$, maternal plasma adiponectin correlated inversely with both BMI before and at the end of pregnancy, but not with total or net GWG, respectively (Table 1). Inverse relationships were observed between maternal adiponectin vs. glucose, C-peptide, insulin, and HOMA-IR. In addition, $\mathrm{MB}$ adiponectin was negatively related to $\mathrm{CB}$ glucose, C-peptide, and triglyceride levels. 
Table 1 General and specific characteristics of study participants and relations with maternal blood adiponectin at delivery

\begin{tabular}{|c|c|c|c|c|}
\hline & NGT & GDM & $P$ value* & $\begin{array}{l}\text { Spearman's } r \text { vs. MB adiponectin } \\
r(P \text { value* })\end{array}$ \\
\hline$n$ & 30 & 25 & & \\
\hline \multicolumn{5}{|l|}{ Maternal } \\
\hline Age (years) & $32.5 \pm 1.0$ & $32.4 \pm 0.9$ & 0.919 & $0.17(0.210)$ \\
\hline Ethnic origin $-n(\%)$ & & & 1.000 & n.a. \\
\hline European & $20(66.7)$ & $16(64.0)$ & & \\
\hline Non-European & $10(33.3)$ & $9(36.0)$ & & \\
\hline Socio-economic status- $n(\%)^{\dagger}$ & & & 0.215 & n.a. \\
\hline Lower SES category & $21(84.0)$ & $20(66.7)$ & & \\
\hline Higher SES category & $4(16.0)$ & $10(33.3)$ & & \\
\hline Smoking in pregnancy (any) $-n(\%)$ & $7(23.3)$ & $3(12.0)$ & 0.318 & n.a. \\
\hline Nulliparous $-n(\%)$ & $4(13.3)$ & $4(16.0)$ & 1.000 & n.a. \\
\hline Height (cm) & $167.0 \pm 1.2$ & $164.6 \pm 1.3$ & 0.246 & $0.23(0.100)$ \\
\hline Prepregnancy weight (kg) & $73.7 \pm 3.9$ & $77.7 \pm 3.8$ & 0.257 & $-0.22(0.114)$ \\
\hline Prepregnancy BMI (kg/m²) & $26.4 \pm 1.3$ & $28.6 \pm 1.3$ & 0.105 & $-0.31(0.021)$ \\
\hline Total GWG (kg) & $17.2 \pm 1.2$ & $14.4 \pm 1.4$ & 0.127 & $0.03(0.848)$ \\
\hline Net GWG (kg) & $13.9 \pm 1.2$ & $9.9 \pm 1.4$ & 0.028 & $0.14(0.363)$ \\
\hline BMl at delivery $\left(\mathrm{kg} / \mathrm{m}^{2}\right)$ & $32.5 \pm 1.5$ & $34.0 \pm 1.2$ & 0.124 & $-0.31(0.023)$ \\
\hline \multicolumn{5}{|l|}{ Blood glucose at oGTT (mg/dL) } \\
\hline Fasting & $79.5 \pm 1.7$ & $99.0 \pm 5.4$ & $<0.001$ & $-0.26(0.086)$ \\
\hline $1 \mathrm{~h}$ & $120.9 \pm 6.3$ & $207.0 \pm 7.2$ & $<0.001$ & $-0.30(0.041)$ \\
\hline $2 \mathrm{~h}$ & $90.3 \pm 4.2$ & $161.4 \pm 9.7$ & $<0.001$ & $-0.18(0.243)$ \\
\hline Area under the curve $(\mathrm{mg} / \mathrm{dL} h)$ & $205.8 \pm 8.2$ & $337.3 \pm 13.5$ & $<0.001$ & $-0.28(0.058)$ \\
\hline Gestational age at delivery (weeks) & $38.3 \pm 0.1$ & $37.8 \pm 0.2$ & 0.028 & $0.03(0.841)$ \\
\hline Mode of delivery $-n(\%)$ & & & 1.000 & n.a. \\
\hline Primary cesarean section & $9(30.0)$ & $7(28.0)$ & & \\
\hline Repeat cesarean section & $21(70.0)$ & $18(72.0)$ & & \\
\hline \multicolumn{5}{|l|}{ Maternal fasting plasma levels at delivery } \\
\hline Adiponectin $(\mu \mathrm{g} / \mathrm{mL})^{\ddagger}$ & $9.9 \pm 0.8$ & $6.7 \pm 0.5$ & 0.002 & n.a. \\
\hline Glucose (mg/dL) & $72.5 \pm 2.0$ & $85.0 \pm 1.2$ & $<0.001$ & $-0.37(0.007)$ \\
\hline Insulin $(\mu \mathrm{U} / \mathrm{mL})$ & $22.3 \pm 2.7$ & $40.1 \pm 8.2$ & 0.217 & $-0.33(0.014)$ \\
\hline HOMA-IR & $3.6 \pm 0.3$ & $8.3 \pm 1.7$ & 0.037 & $-0.36(0.009)$ \\
\hline C-peptide (ng/mL) & $2.0 \pm 0.2$ & $4.9 \pm 0.7$ & $<0.001$ & $-0.53(<0.001)$ \\
\hline Leptin (ng/mL) & $28.9 \pm 3.5$ & $18.0 \pm 2.6$ & 0.017 & $0.04(0.772)$ \\
\hline Triglycerides (mmol/L) & $2.4 \pm 0.1$ & $2.3 \pm 0.1$ & 0.554 & $0.11(0.413)$ \\
\hline \multicolumn{5}{|l|}{ Birth outcome/newborn } \\
\hline Female sex-n (\%) & $18(60.0)$ & $11(44.0)$ & 0.285 & n.a. \\
\hline Placental weight (g) & $658.7 \pm 28.4$ & $612.5 \pm 37.8$ & 0.337 & $-0.15(0.328)$ \\
\hline Birth weight (g) & $3368 \pm 87$ & $3578 \pm 82$ & 0.038 & $-0.22(0.113)$ \\
\hline Birth length $(\mathrm{cm})$ & $51.1 \pm 0.5$ & $50.9 \pm 0.3$ & 0.890 & $-0.03(0.858)$ \\
\hline Relative birth weight $(\mathrm{g} / \mathrm{cm})$ & $65.8 \pm 1.3$ & $70.3 \pm 1.5$ & 0.022 & $-0.23(0.098)$ \\
\hline Macrosomia-n (\%) & $3(10.0)$ & $4(16.0)$ & 0.689 & n.a. \\
\hline LGA-n (\%) & $3(10.0)$ & $9(36.0)$ & 0.026 & n.a. \\
\hline Hypoglycemia-n (\%) & $1(3.6)$ & $6(24.0)$ & 0.043 & n.a. \\
\hline
\end{tabular}


Table 1 General and specific characteristics of study participants and relations with maternal blood adiponectin at delivery (Continued)

\begin{tabular}{lllll}
\hline & NGT & GDM & $P$ value* & $\begin{array}{l}\text { Spearman's } r \text { vs. MB adiponectin } \\
r(P \text { value* })\end{array}$ \\
\hline Cord blood plasma levels & & & \\
Adiponectin $(\mu \mathrm{g} / \mathrm{mL})$ & $25.8 \pm 1.6$ & $28.5 \pm 2.4$ & 0.488 & $0.18(0.182)$ \\
Glucose $(\mathrm{mg} / \mathrm{dL})$ & $61.6 \pm 2.0$ & $72.0 \pm 1.9$ & 0.001 & $-0.33(0.015)$ \\
Insulin $(\mu \mathrm{U} / \mathrm{mL})$ & $19.2 \pm 2.0$ & $26.9 \pm 2.9$ & 0.042 & $-0.13(0.366)$ \\
HOMA-IR & $3.1 \pm 0.4$ & $5.0 \pm 0.6$ & 0.003 & $-0.22(0.117)$ \\
C-peptide $(\mathrm{ng} / \mathrm{mL})$ & $1.0 \pm 0.1$ & $1.6 \pm 0.1$ & $<0.001$ & $-0.31(0.023)$ \\
Leptin $(\mathrm{ng} / \mathrm{mL})$ & $10.8 \pm 1.7$ & $15.2 \pm 2.6$ & 0.247 & $-0.21(0.130)$ \\
Triglycerides $(\mathrm{mmol} / \mathrm{L})$ & $1.1 \pm 0.1$ & $1.8 \pm 0.1$ & $<0.001$ & $-0.40(0.003)$ \\
\hline
\end{tabular}

Data are means \pm SEM or $n(\%)$

NGT normal glucose tolerance, GDM gestational diabetes mellitus, MB maternal blood, n.a. not applicable, SES socio-economic status, BMI body mass index, GWG gestational weight gain, OGTT oral glucose tolerance test, HOMA-IR homeostatic model assessment of insulin resistance, LGA large-for-gestational age newborn * Statistical significant $(P$ value $<0.05)$

${ }^{\dagger} \mathrm{SES}$ was categorized as previously described [36]

${ }^{\ddagger}$ Continued to be significantly different between the groups after adjustment for prepregnancy BMI $(P=0.006)$ and BMI at delivery $(P=0.004)$

\section{Birth and newborn outcomes}

Offspring of GDM women were significantly heavier at birth but similar in length compared to newborns of the NGT group (Table 1). CB plasma levels of glucose, insulin, C-peptide, and triglycerides were significantly increased in newborns of GDM mothers, accompanied by elevated HOMA-IR and leptin levels. There was no significant difference of $\mathrm{CB}$ adiponectin concentrations between the groups. Furthermore, female and male neonates showed equal amounts of $\mathrm{CB}$ adiponectin (female $27.8 \pm$ $1.4 \mu \mathrm{g} / \mathrm{mL}$ vs. male $26.3 \pm 2.5 \mu \mathrm{g} / \mathrm{mL}, P=0.299)$. In the whole cohort, no correlations were present between $\mathrm{CB}$ adiponectin and newborns' anthropometry or CB metabolites/hormones. However, sex-specific subgroup analyses revealed positive associations between $\mathrm{CB}$ adiponectin vs. insulin and HOMA-IR in male neonates (insulin, $r=0.41$, $P=0.037$; HOMA-IR, $r=0.41, P=0.042$ ).

\section{ADIPOQ gene expression in maternal adipose tissues}

In both adipose tissue types, gene expression of $A D I P O Q$ was significantly reduced in women with GDM (Fig. 1a, b). On average, diabetic subjects had $20-30 \%$ less mRNA levels compared to controls, with the difference higher in VAT than SAT. Again, these group differences were even independent of maternal BMI (adjusted for prepregnancy BMI-SAT: $P=0.049$, VAT: $P=0.008$, SAT+VAT: $P=$ 0.002; adjusted for BMI at delivery-SAT: $P=0.037$, VAT: $P=0.006$, SAT+VAT: $P=0.001)$. Across the whole cohort, VAT, but not SAT, and ADIPOQ mRNA levels were inversely associated with maternal glucose concentrations at oral glucose tolerance test (oGTT) and at delivery (fasting glucose at oGTT: $r=-0.33, P=0.029$; area under the curve of glucose (AUCG) at oGTT: $r=-0.43, P=0.004$; fasting glucose at delivery: $r=-0.29, P=0.040$ ). Gene expression in both fat depots was positively associated with maternal circulating adiponectin levels across the whole cohort (Fig. 1c-e), irrespective of the BMI (adjusted for prepregnancy BMI-SAT: $R=0.44, P=0.001$, VAT: $R=$ 0.34, $P=0.017$; SAT+VAT: $R=0.51, P<0.001$; and adjusted for BMI at delivery-SAT: $R=0.45, P=0.001$, VAT: $R=$ $0.35, P=0.015 ;$ SAT+VAT: $R=0.52, P<0.001)$. SAT plus VAT mRNA levels showed the strongest correlations with plasma adiponectin.

\section{DNA methylation at the $A D I P O Q$ gene locus in maternal tissues}

The overall DNA methylation pattern of the analyzed regions at the ADIPOQ gene locus was similar in SAT and VAT (Fig. 2b, c). All investigated CpG sites $(n=10)$ had moderate to high methylation levels (>50\%). Region R1 was hypermethylated as compared to R2 and R3. A generally higher variability of DNA methylation was observed in R2 and R3 in both fat depots.

In SAT, DNA methylation was consistent between both groups. Statistically, only the comparison at R2 CpG2 was close to significance $(P=0.056)$. Although similar to SAT regarding the overall pattern, methylation in VAT showed slightly less variability in R2 and R3. By groups, methylation of R3 in VAT appeared tighter in GDM subjects. Furthermore, DNA methylation of the two CpG sites was significantly altered in VAT of women with GDM vs. NGT. Compared to controls, R1 CpG4 was lower and R3 CpG1 higher methylated in VAT of the diabetic group (Fig. 2c). The mean methylation difference was around $2.1-2.4 \%$. To evaluate the potential functional relevance of these two CpG sites, correlation analyses between DNA methylation at R1 CpG4 and R3 CpG1 and VAT gene expression were performed (Fig. 2f, g). Here, only the position R3 CpG1 showed a significant inverse relationship with mRNA levels. Further inverse correlations were found 

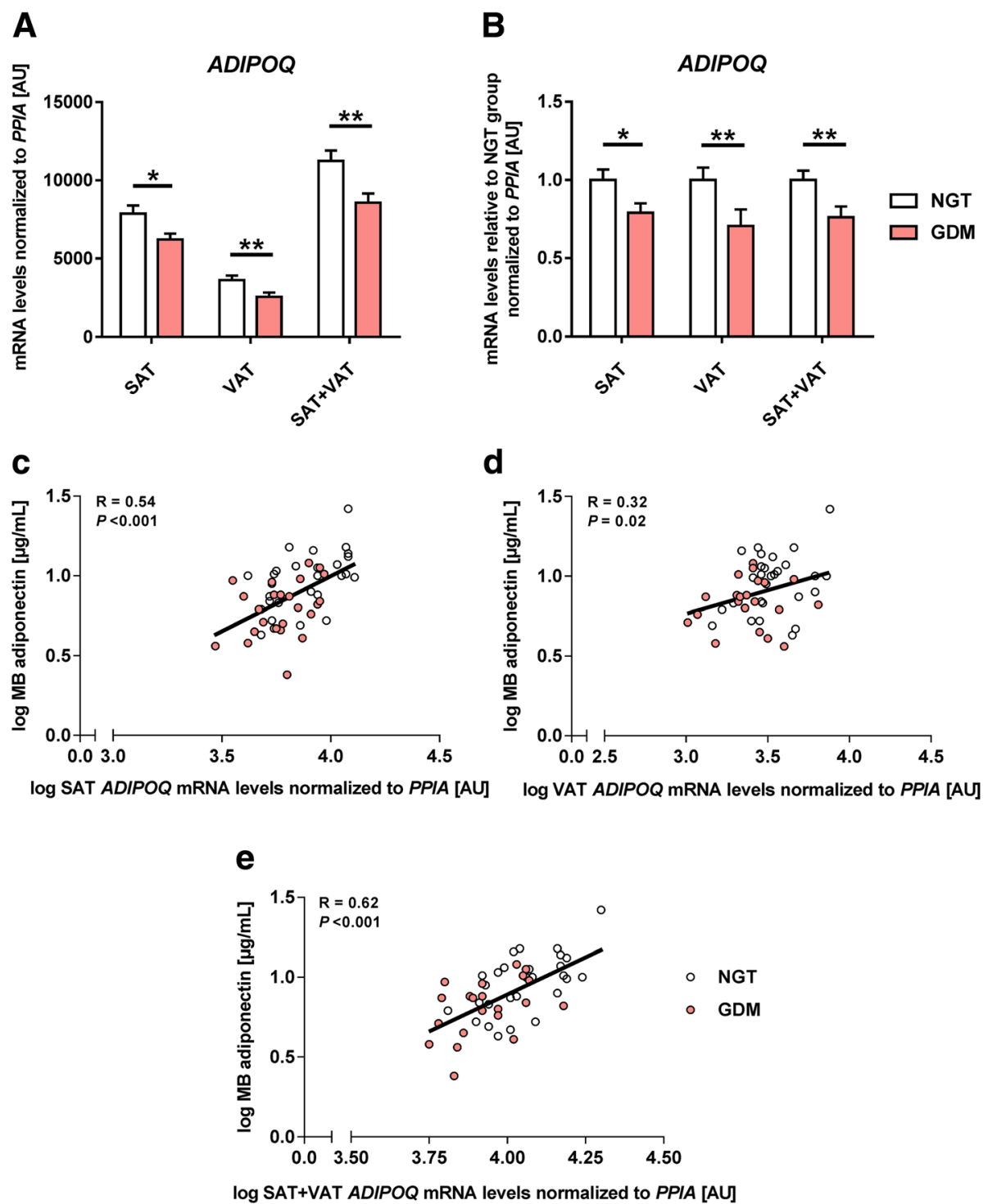

Fig. 1 Adiponectin mRNA levels in adipose tissues of women with NGT vs. GDM and their relations to plasma adiponectin. Gene expression of adiponectin (ADIPOQ) normalized to peptidylprolyl isomerase A (PPIA) analyzed in subcutaneous (SAT) and visceral adipose tissues (VAT), respectively, of normal glucose tolerance women (NGT; open bars; $n=30$ ) vs. women with gestational diabetes mellitus (GDM; red bars; $n=22-25)$. Sum of expression of both fat depots (SAT+VAT) is plotted additionally (a-b). Data are means \pm SEM, shown as raw data (a) or percentage of NGT levels (b). Pearson's correlation coefficients $(R)$ calculating the relationship between maternal blood (MB) adiponectin levels and adipose tissue gene expression data (c-e). NGT, open circles; GDM, red circles. AU, arbitrary units. ${ }^{*} P<0.05$, ${ }^{*} P<0.01$

between gene expression and single CpG sites and/or mean methylation levels regarding $\mathrm{R} 2$ and $\mathrm{R} 3$, but not $\mathrm{R} 1$, across both fat depots. For example, the means of R2 and $\mathrm{R} 3$ were negatively associated with respective mRNA levels (SAT-R2 mean: $R=-0.31, P=0.030$, R3 mean: $R=-0.40$, $P=0.008$; VAT - R2 mean: $R=-0.33, P=0.020$, R3 mean: $R=-0.45, P=0.003)$. Among all individual CpGs and the means of R1-R3, VAT CpG1 and CpG2 of R3 DNA methylation showed relations to maternal glucose levels, which were in a positive direction (CpG1-AUCG at oGTT: $r=0.37, P=0.023$; fasting glucose at delivery: $r=0.32$, $P=0.034$; CpG2-AUCG at oGTT: $r=0.34, P=0.038)$.

Despite the similarity of methylation pattern between SAT and VAT, cross-tissue correlations were rare and inconsistent. While R1 CpG1 and CpG2 patterns were inversely associated between both fat types (R1 CpG1: $r=-0.35, P=0.014 ; \mathrm{R} 1 \mathrm{CpG} 2: \quad r=-0.53, \quad P<0.001)$, methylation at R2 CpG1 and R2 mean was related in a positive manner (R2 CpG1: $r=0.32, P=0.025$; R2 mean: $r=0.30, P=0.041)$. 

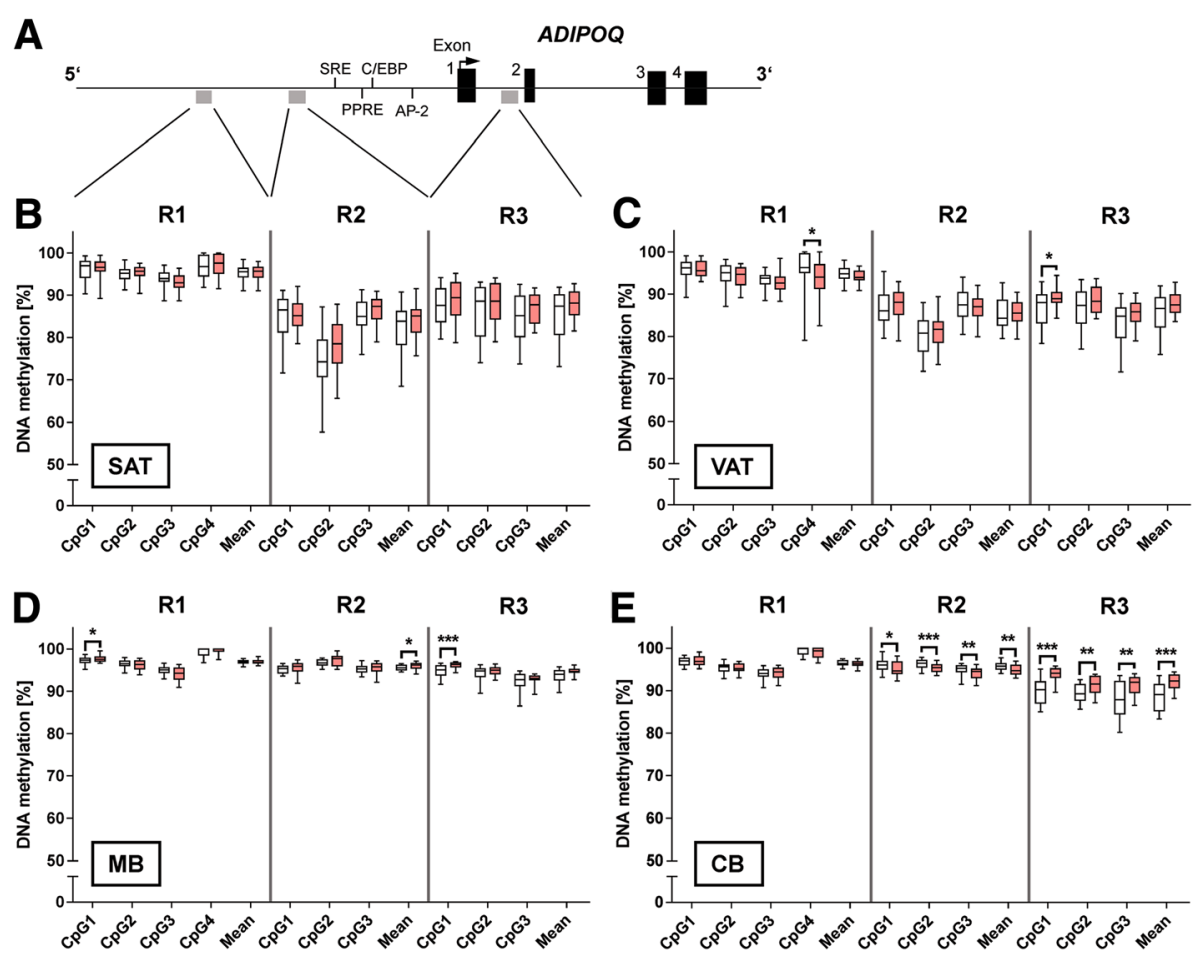

$\square$ NGT $\square$ GDM
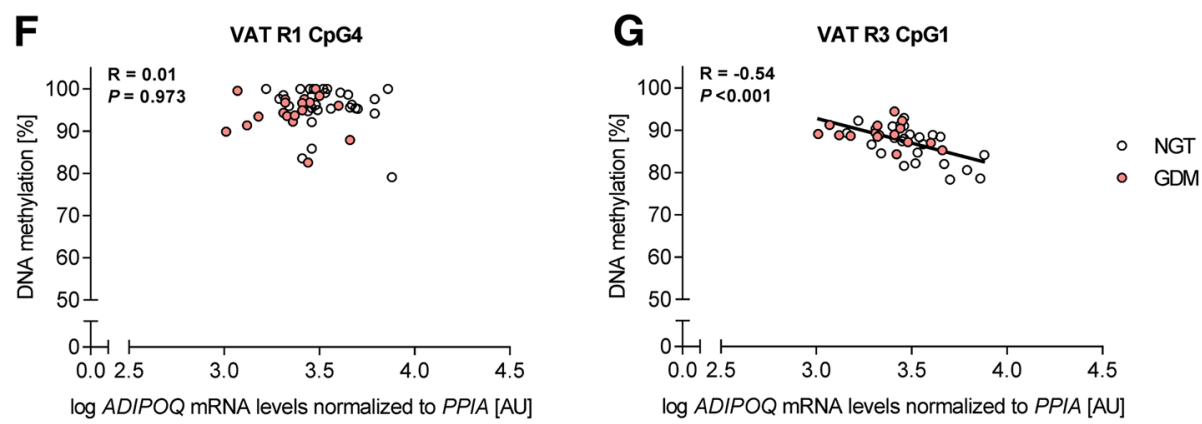

Fig. 2 CpG site-specific DNA methylation analyses at the adiponectin gene locus in adipose tissues and blood cells from mothers with NGT vs. GDM and their offspring. Schematic illustration of the adiponectin (ADIPOQ) gene locus, including characterized transcription factor binding sites (e.g., SRE, PPRE, C/EBP), and analyzed DNA methylation assays (R1-R3) (a). Percent DNA methylation is shown for each individual CpG site (numbering follows 5' to 3'), analyzed per assay (R1-R3) for subcutaneous adipose tissue (SAT; b), visceral adipose tissue (VAT; c), maternal blood $(\mathrm{MB} ; \mathbf{d})$, and cord blood (CB; e) in the normal glucose tolerant (NGT; open boxes; $n=30$ ) vs. gestational diabetes mellitus group (GDM; red boxes; $n=22-25)$. Group comparisons in cord blood samples were adjusted for newborn sex. Box-whisker plots show the minimum and maximum values. Pearson's correlation coefficients $(R)$ were calculated to determine the relationships between DNA methylation of significant CpG sites and respective ADIPOQ mRNA levels in VAT across the whole cohort $(\mathbf{f}, \mathbf{g})$. Gene expression of ADIPOQ was normalized to peptidylprolyl isomerase A (PPIA). NGT, open circles; GDM, red circles. AU, arbitrary units. ${ }^{*} P<0.05,{ }^{* *} P<0.01,{ }^{* *} P<0.001$

As compared to adipose tissues, MB was characterized by overall higher and rather tight methylation pattern (mostly $>90 \%$; Fig. 2d). With regard to R3, the GDM group showed less variability compared to women with NGT, as observed in VAT. Group differences were detected at R1 CpG1, R2 mean, and R3 CpG1 (mean differences around 0.4-1.4\%). Similar to VAT, R3 CpG1 in MB was hypermethylated in the GDM group. However, no correlation was found between methylation of VAT and MB.

\section{Cord blood DNA methylation at the $A D I P O Q$ gene locus} To evaluate a potential GDM effect on fetal DNA methylation, all regions were analyzed in $\mathrm{CB}$ cells, too. Across all investigated tissues, the $\mathrm{CB}$ methylation pattern was most similar to $\mathrm{MB}$, showing the overall low variability (Fig. 2e). However, higher variation was observed at R3 in $\mathrm{CB}$ vs. $\mathrm{MB}$, while methylation in $\mathrm{CB}$ from GDM-exposed newborns was more "compact." In comparison to controls, GDM offspring were characterized by significant 
hypomethylation at all $\mathrm{CpG}$ sites and, accordingly, the mean of R2 (mean differences around 1\%), while significant hypermethylation at all R3 CpG sites and the mean of R3 were observed (mean differences around 1.7-4.0\%); even after adjustment for newborn sex (Fig. 2e). The most pronounced difference was observed at R3 CpG1, which followed the same pattern as in MB and VAT by showing higher methylation in the GDM group.

By analyzing the same CPG positions between maternal tissues and $\mathrm{CB}$, the only positive correlations were found with the methylation levels of $\mathrm{R} 3$ of $\mathrm{MB}$ (CpG1: $r=0.51, P=0.001 ;$ CpG2: $r=0.43, P=0.008$; CpG3: $r=0.47, P=0.003)$. There were no relationships present between maternal age, prepregnancy BMI, total GWG, gestational age, or $\mathrm{MB}$ hormones and the $\mathrm{CB}$ methylation levels of these significant different regions. The mean CB DNA methylation levels of R2 correlated inversely with maternal BMI at delivery $(r=-0.31, P=0.031)$ and AUCG at oGTT $(r=-0.38, P=0.013)$. On the contrary, the mean DNA methylation levels of R3 were unrelated to maternal BMI but showed positive associations with AUCG at oGTT and fasting glucose at delivery (AUCG at oGTT: $r=0.45, P=0.004$; fasting glucose at delivery: $r=-0.44, P=0.003$ ). Furthermore, Spearman's correlations revealed significant inverse relationships between R2 CpG1 and mean R2 methylation vs. (relative) birth weight (birth weight vs. R2 CpG1: $r=-0.32, P=0.024$; relative birth weight vs. R2 CpG1: $r=-0.36, P=0.012$; R2 mean: $r=-0.32, P=0.024)$. Furthermore, methylation of R3 CpG1, CpG3, and R3 mean was positively associated with CB adiponectin (R3 CpG1: $r=0.34, P=0.024$; R3 CpG3: $r=0.38, P=0.011$; R3 mean: $r=0.34, P=0.022$ ).

\section{Discussion}

This study demonstrates that plasma adiponectin and its gene expression in the two major adipose tissue types is consistently decreased in women with treated GDM as compared to matched healthy subjects, even independent of their BMI. Furthermore, our data indicate that DNA methylation of previously published regions (i.e., R2 and R3) indeed may be involved in respective gene regulation but are just slightly altered in patients with GDM. Overall, fat tissue DNA methylation patterns are not reliably reflected in $\mathrm{MB}$ cells. $\mathrm{CB}$ ADIPOQ DNA methylation profiles of R2 and R3, however, are significantly altered in affected offspring, irrespective of fetal sex, and associated with their phenotypic parameters.

The present study confirms that GDM is characterized by hypoadiponectinemia [7]. In addition, plasma adiponectin levels appear to be more related to the insulin-resistant state than to the maternal BMI/GWG, decisively specifying observations from other reports [6, 26]. Interestingly, GDM was associated here with significantly lower net GWG and circulating leptin levels at delivery. This may imply less gestational adipose tissue accretion in these subjects, potentially due to GDM treatment. Thus, although adiposity became apparently reduced in the GDM group, adiponectin was still significantly decreased in comparison to controls. This argues in favor of a genuine GDM rather than a BMI (adiposity) effect. Considering its critical functions in enhancing insulin sensitivity and glucose/lipid disposal/oxidation, decreased adiponectin levels therefore probably affect materno-fetal metabolism and, consequently, nutrient supply to the fetus in GDM. Indeed, maternal adiponectinemia was inversely associated with blood glucose and HOMA-IR in both mothers and newborns. Potentially, this has adverse short- and long-term implications for the GDM offspring $[4,25]$.

$\mathrm{CB}$ adiponectin levels were similar between the groups and female/male offspring which support the findings from other studies [27, 28]. Interestingly, there was a positive link between $\mathrm{CB}$ adiponectin and insulin/insulin resistance in male offspring, which appears paradox compared with the adult situation, where adiponectin levels usually decline with increasing insulin resistance $[6,12]$. However, $C B$ adiponectin has been also suggested as a growth factor in early life [14, 27, 29], which may involve temporary synergistic effects with insulin. Fetal insulin is a potent anabolic factor contributing to higher in utero growth and has also been identified as a critical hormone for the early "programming" of later metabolic disease risk [30].

In adults, production of adiponectin is primarily located in white adipocytes [5]. Our data revealed reduced mRNA expression in SAT and VAT of women with GDM, even after adjustment for BMI. Reduced fat tissue expression, moreover, obviously affected the circulating plasma levels, as indicated by correlation analyses. Expression in both fat depots was associated with plasma adiponectin, while the relationship with the sum of SAT +VAT actually was the strongest. Interestingly, a large number of studies focused on circulating adiponectin [7], but only two investigated its expression in adipose tissues from women with GDM $[19,20]$. In extension to these previous reports, the present study clearly shows altered $A D I P O Q$ gene expression in SAT as well as VAT of GDM, even independent of their BMI. While the decrease in mRNA levels was relatively similar in both SAT and VAT in GDM subjects, the difference was more pronounced in VAT. In addition, maternal glucose levels were associated with VAT mRNA only indicating a particular regulatory role of VAT $A D I P O Q$ gene expression on maternal glycemia. As the differential mRNA profiles are possibly a consequence of altered transcriptional mechanisms, analysis of regulatory factors appears critical to better understand the potential causes of this observation.

To the best of our knowledge, this is the first study determining DNA methylation of ADIPOQ in adipose 
tissues from women with GDM and NGT. Both fat depots were characterized by overall similar DNA methylation patterns irrespective of women's glucose tolerance. Furthermore, methylation of R2 and R3 was inversely associated with gene expression in SAT and VAT indicating the functional relevance of these two regions. While region $\mathrm{R} 2$ is able to serve as a transcription binding site for a variety of factors [23], a regulatory function of the intronic region R3 is unknown [22]. Interestingly, VAT R3 CpG1 was hypermethylated in GDM subjects as compared to controls. As DNA methylation at this site was correlated inversely with gene expression, this alteration might contribute to reduced transcription in VAT of women with GDM. However, the mean group difference was rather small, and therefore, it remains open if it plays, indeed, a relevant role. Thus, alterations of other regulatory mechanisms may be responsible for decreased mRNA levels. Moreover, there were obvious adipose tissue-specific DNA methylation patterns that were not associated with and reflected in DNA methylation of MB cells, even though only R3 CpG1 showed a consistent signature in $\mathrm{MB}$ and VAT across groups. Therefore, based on our findings, blood DNA methylation of investigated regions can hardly serve as a reliable indicator/ biomarker for adipose tissue methylation. Beyond the addressed study subject, this observation appears to deserve particular attention.

Exposure to a diabetic intrauterine environment may program the offspring for a higher susceptibility for "diabesity" development later in life [4, 25]. Alterations of DNA methylation are suggested to contribute to this phenomenon [25]. Pioneer work by Bouchard et al. [22] observed the relationships between maternal glucose levels at oGTT and placental DNA methylation of the two regions investigated here (R1 and R3). Intriguingly, we found indeed a significantly altered methylation pattern of R2 and R3, but not R1, in CB of GDM newborns. Moreover, maternal glucose at oGTT and/or at delivery was related to CB DNA methylation levels of R2 and, in particular, R3, which may suggest a potential influence of maternal hyperglycemia itself. Of note, R2 and R3 may be involved in gene regulation, as indicated by the adipose tissue data. In all cases, however, the mean methylation differences were rather small, as in other studies [31-33]. Paradoxically, the region R2 was consistently hypomethylated here, but R3 was hypermethylated at each analyzed $\mathrm{CpG}$ site in $\mathrm{CB}$ of GDM newborns. Considering the functional relevance of $\mathrm{R} 2$ as recently described [23], lower methylation could fit with the slightly higher circulating adiponectin levels observed in the GDM offspring. Since it is unclear whether $A D I P O Q$ is expressed in $\mathrm{CB}$ cells, our ability to speculate about functional consequences of the observed alterations for $A D I P O Q$ expression in the offspring is limited.
The associations found between methylation of R2 and (relative) birth weight seem to fit with the idea that lower methylation in $\mathrm{R} 2$ is related to increased $A D I P O Q$ expression. Furthermore, it has been shown that $\mathrm{CB}$ adiponectin is positively associated with birth weight [27, 29]. However, the positive relation between methylation of R3 and CB adiponectin appears not in agreement with a functional role of R3, as higher methylation would result in lower expression. Notably, R3 CpG1 was hypermethylated in three tissues, i.e., VAT, $\mathrm{MB}$, and $\mathrm{CB}$, in the GDM group and might therefore have a diagnostic/ predictive potential for adiponectin dysregulation. Nevertheless, we cannot exclude that this finding has no decisive functional implications for the offspring, as $\mathrm{CB}$ adiponectin was not significantly altered in GDM offspring, and apparently, blood cells did not reflect maternal adipose tissue methylation. Interestingly and worth noting, however, a very recent study in adults born to mothers with GDM is showing significantly increased $A D I P O Q$ DNA methylation, accompanied with lower gene expression in SAT [34].

A study limitation is that whole tissue biopsies were investigated, a common approach in the majority of such studies [19, 20, 22], and therefore, we cannot exclude that differences in cell-type heterogeneity between tissues, subjects, or GDM patients and controls influenced the molecular results. Furthermore, as adipose tissues are the major source of adiponectin, our expression analyses were solely in SAT and VAT and not in maternal and fetal blood cells, limiting our ability to evaluate the functional implications of blood DNA methylation on transcription. Still, as adipose tissues and other fetal tissues have been identified as tissues of origin for adiponectin in the newborn [35], the relative contribution of $\mathrm{CB}$ adiponectin expression, if there is any, to circulating levels might be comparably small. Larger human studies might be beneficial to evaluate the sex-specific effects of the role of fetal adiponectin and DNA methylation profiles in fetal tissues.

\section{Conclusions}

In conclusion, reduced adipose tissue $A D I P O Q$ expression appears to be a genuine pathogenic co-factor in GDM, even irrespective of the maternal weight status. Accompanying, the DNA methylation of the two functional characterized regions ( $\mathrm{R} 2$ and $\mathrm{R} 3$ ) is altered in $\mathrm{CB}$ cells of GDM-exposed newborns. Thus, future studies, especially in adiponectin-source tissues, should further evaluate the pathogenic, diagnostic, and/or therapeutic capability of adiponectin in GDM as well as the potential intrauterineacquired DNA methylation patterns that affect gene transcription and, consequently, the phenotypic outcome and "diabesogenic" risk of GDM offspring. 


\section{Methods}

This investigation is part of the prospective observational "Early CHARITÉ (EaCH)" cohort study [36]. Twenty-five women with GDM and 30 women with NGT were prospectively recruited before the scheduled delivery of singletons via cesarean section (CS) at the Clinic of Obstetrics of the Charité - Universitätsmedizin Berlin, Campus Virchow-Klinikum, Germany. Recruitment, exclusion criteria, standardized procedures, analytical methods, etc. are described in detail elsewhere [36]. The groups were matched for maternal age, ethnic origin, socio-economic status (SES), parity, and, in particular, prepregnancy BMI. Research design and methods were conducted in accordance with the Declaration of Helsinki, revised in 2004, and approved by the local Ethics Committee (EA2/026/04). Informed written consent was obtained from all subjects.

\section{Subject data}

Maternal data were collected as previously described [36]. Briefly, maternal height and weight before conception and the last measured weight within 1 week prior to delivery were abstracted from the "Mutterpass" (a standardized maternity record in Germany), and the BMI was calculated. Total gestational weight gain (GWG) was calculated as the difference between prepregnancy weight and nearest weight to delivery. Furthermore, to estimate the genuine maternal body habitus, net GWG was generated by subtracting birth weight and placental weight from women's total GWG. GDM screening was performed between the 24th and 28th week of gestation according to the national guidelines at the time of recruitment [37, 38]. Patients with GDM were treated either by dietary therapy alone or in combination with insulin therapy $(n=13)$ to achieve glucose targets according to the abovementioned guidelines [37, 38].

Newborn characteristics were abstracted from medical records. Anthropometric outcomes included birth weight, relative birth weight $(\mathrm{g} / \mathrm{cm})$, and macrosomia (defined as birth weight $\geq 4000 \mathrm{~g}$ ). Further clinical parameters, including placental weight, were determined as described elsewhere [36].

\section{Blood and adipose tissue sampling}

Fasting maternal venous blood was collected prior to CS and venous umbilical $\mathrm{CB}$ was drawn immediately after birth and cord clamping. For further analyses, fractions of plasma and blood cells were stored separately at $-80{ }^{\circ} \mathrm{C}$. Paired abdominal SAT and omental VAT biopsies were obtained during CS, snap frozen in liquid nitrogen, and stored at $-80{ }^{\circ} \mathrm{C}$. For technical reasons, in one GDM subject, it was not possible to collect the VAT sample.

\section{Blood hormone and metabolite analyses}

Total plasma adiponectin was determined using a specific commercially available ELISA (Cat\# RD191023100, BioVendor, Brno, Czech Republic). Plasma insulin, C-peptide, and leptin levels were measured using commercially available radioimmunoassays (insulin, Cat\# RIA-1249; C-peptide, Cat\# RIA-1252; leptin, Cat\# RIA-1624; DRG Instruments, Marburg, Germany). The following are the inter-assay coefficients of variance: adiponectin $6.0 \%$, insulin 3.4-6.0\%, C-peptide 2.4-9.3\%, and leptin 3.6-6.2\%. Plasma glucose and triglyceride concentrations were quantified using the oxidase-peroxidase and the glyceride-3phosphatoxidase-peroxidase method (both obtained from Dr. Lange, Berlin, Germany). As an indicator of insulin resistance, the homeostatic model assessment (HOMA-IR) was calculated [39].

\section{Adipose tissue gene expression analyses}

Total RNA was isolated from $100 \mathrm{mg}$ adipose tissue using the RNeasy Lipid Tissue Mini Kit (Qiagen, Hilden, Germany) according to the manufacturer's protocol, including DNase treatment (Qiagen). Quantity and purity were assessed with a spectrophotometer (NanoDrop 1000, Thermo Scientific, Wilmington, DE, USA). Quality was evaluated using the Bioanalyzer 2100 (Agilent Technologies, Santa Clara, CA, USA). Overall, the samples showed high RNA integrity numbers (RIN; SAT: $7.8 \pm 0.1$, VAT: $7.7 \pm 0.1)$; however, two VAT samples of the GDM group had to be excluded due to lower RNA quality (RIN <6). For cDNA synthesis, 300 ng RNA was reverse transcribed using the iScript kit (Bio-Rad, Hercules, CA, USA) as recommended by the manufacturer. Quantitative real-time PCR was performed using TaqMan technology (Applied Biosystems, Waltham, MA, USA) in combination with a 7500 instrument (Applied Biosystems). All samples were run in triplicate, and all plates included respective controls to ensure run quality and confirm the absence of contamination. Protocol conditions were as follows: denaturation at $95{ }^{\circ} \mathrm{C}$ for $10 \mathrm{~min}$, followed by 40 two-step cycles at $95^{\circ}$ $\mathrm{C}$ for $15 \mathrm{~s}$ and $60{ }^{\circ} \mathrm{C}$ for $1 \mathrm{~min}$. A pre-designed exon-exon spanning TaqMan primer assay for $A D I P O Q$ was obtained from Applied Biosystems (ID: Hs00605917_m1) and amplified in dualplex with the housekeeping gene peptidylprolyl isomerase A (PPIA; ID: Hs99999904_m1). ADIPOQ gene expression was normalized using the $2^{-\triangle C t}$ method, including the correction for amplification efficiency calculated from standard curves of each primer set. Gene expression of PPIA was stable, as in a previous housekeeping gene study for adipose tissue [40], and was identical between the groups in both fat depots (SAT: $23.76 \pm 0.09$ vs. $23.72 \pm 0.12$; VAT: $23.39 \pm 0.10$ vs. $23.51 \pm 0.08$; NGT vs. GDM; arbitrary units). As both adipose tissue types contribute to circulating adiponectin, a sum of SAT and VAT mRNA levels was calculated and additionally analyzed. 


\section{DNA methylation analyses}

Genomic DNA was extracted from $30 \mathrm{mg}$ adipose tissue and $1 \mathrm{~mL}$ blood, respectively, using the Genomic DNATissue kit or the Quick-gDNA Blood kit (both obtained from Zymo Research, Irvine, CA, USA), following the manufacturer's protocols. Quantity and purity of DNA were assessed with NanoDrop (Thermo Scientific). Sodium bisulfite treatment was performed on $400 \mathrm{ng}$ DNA using the EZ DNA Methylation-Gold kit (Zymo Research) as recommended by the manufacturer. In silico analyses revealed that the $A D I P O Q$ promoter has no classical CpG island and contains a low number of $\mathrm{CpG}$ sites (chromosomal location chr3:186,556,516-186,580,200, UCSC Genome browser on human Feb. 2009, GRCh37/hg19 assembly). Furthermore, characterized transcription factor binding sites, e.g., PPRE, SRE, include no CpG site $[21,41-44]$. Thus, assays were selected based on recently published regions, obviously important for $A D I P O Q$ gene regulation [22, 23]. The following regions were analyzed: R1 and R3 (similar to region "C" and "E" in Bouchard et al. [22]) and R2 (similar to "R2" in Kim et al. [23]). Methylation assays were designed using the PyroMark Assay Design Software v. 2.0 (Qiagen), and detailed information is given in Additional file 1: Table S1. Pyrosequencing was performed on amplified PCR products with the PyroMark Q24 pyrosequencer (Qiagen) as previously described [45]. Percent methylation was analyzed across individual CpG sites located within the following regions of interest: R1 (four CpGs), R2 (three CpGs), and R3 (three CpGs). Bisulfite treatment and pyrosequencing assays were tested and reproducibility validated using duplicate samples, various tissue types, and methylation scales $(0-100 \%)$.

\section{Statistical analyses}

Data are presented as means \pm SEM or number and percentage. Continuous variables were evaluated for normal distribution using Shapiro-Wilk tests. If necessary, skewed data were logarithmically transformed to achieve normal distribution. Group comparisons were analyzed by unpaired $t$ test or Mann-Whitney $U$ test or chi-squared/Fisher's exact test, as appropriate. ANCOVA was used to adjust for maternal BMI or newborn sex. To assess the associations between clinical and/or endocrine parameters and DNA methylation, Spearman's correlation coefficients $(r)$ were calculated. Pearson's correlations coefficients $(R)$ were used to test the relationships between molecular data, i.e., circulating adiponectin levels, gene expression, and DNA methylation. Potential confounding effects of maternal BMI were checked with partial Pearson's correlations. Statistical analyses were performed using SPSS v. 24.0 (IBM, Armonk, NY, USA). A $P$ value $<0.05$ was considered significant (two-tailed).

\section{Additional file}

Additional file 1: Table S1. Primer information for DNA methylation analyses. (DOCX $14 \mathrm{~kb}$ )

\section{Abbreviations}

ADIPOQ: Adiponectin gene; ANCOVA: Analysis of covariance; AUCG: Area under the curve of glucose; BMI: Body mass index; C/EBP: CCAAT/enhancerbinding protein; CB: Cord blood; CpG: Cytosine-guanine dinucleotide; CS: Cesarean section; EaCH: Early CHARITÉ study; ELISA: Enzyme-linked immunosorbent assay; GDM: Gestational diabetes mellitus; GWG: Gestational weight gain; HOMA-IR: Homeostatic model assessment of insulin resistance; LGA: Large-for-gestational age; MB: Maternal blood; n.a.: Not applicable; NGT: Normal glucose tolerant; OGTT: Oral glucose tolerance test; PPIA: Peptidylprolyl isomerase A; PPRE: Peroxisome proliferator-activated receptor response element; RIN: RNA integrity number; SAT: Subcutaneous adipose tissue; SES: Socio-economic status; SRE: Sterol regulatory element; VAT: Visceral adipose tissue

\section{Acknowledgements}

The authors acknowledge Thomas Harder, MD; Andrea Loui, MD; Elisabeth Eilers, MD; and Sandra Schulz, MSc, for the contributions to the initial study cohort design, subject recruitment, and sample/data collection. We are very grateful to all the participants of this study as well as the midwives and staff of the Clinic of Obstetrics at the Charité, Campus Virchow-Klinikum, Berlin, Germany, for their support in the subject recruitment and sample/data collection.

\section{Funding}

This study was supported in part by grants of the German Research Foundation (DFG: PL-241/5-1, GRK 1208) to Dr. Plagemann. The funder had no role in the study design, data collection and analysis, decision to publish, or preparation of the manuscript. We acknowledge support from the Open Access Publication Fund of Charité - Universitätsmedizin Berlin.

\section{Availability of data and materials}

The datasets used and/or analyzed during the current study are available from the corresponding author on reasonable request.

\section{Authors' contributions}

$\mathrm{RO}$ contributed to the design and conceptualization of the study, performed the experiments, analyzed and interpreted the data, and wrote the original draft. JHS contributed to the design and conceptualization of the study and data collection and reviewed the final draft. KM was involved in the data collection/management and laboratory measurements and reviewed the final draft. KS contributed to the data collection/management and interpretation and reviewed the final manuscript. TZ performed the laboratory measurements and revised the final manuscript. JWD contributed to the study design, provided the resources, and revised the final draft. WH provided the resources and reviewed the final draft. RCR contributed to the design and conceptualization of the study, performed the experiments, analyzed and interpreted the data, and wrote the original draft. AP contributed to the design and conceptualization of the study, analyzed and interpreted the data, and wrote the original draft. All authors critically read and approved the final manuscript.

\section{Ethics approval and consent to participate}

Research design and methods were conducted in accordance with the Declaration of Helsinki, revised in 2004, and approved by the local Ethics Committee (Ethikausschuss 2 am Campus Virchow-Klinikum, Charité Universitätsklinikum Berlin, EA2/026/04). All participants provided written informed consent before inclusion into the study.

Consent for publication

Not applicable.

Competing interests

The authors declare that they have no competing interests. 


\section{Publisher's Note}

Springer Nature remains neutral with regard to jurisdictional claims in published maps and institutional affiliations.

\section{Author details \\ 'Division of 'Experimental Obstetrics,' Clinic of Obstetrics, Charité - Universitätsmedizin Berlin, Corporate Member of Freie Universität Berlin Humboldt-Universität zu Berlin, and Berlin Institute of Health, Campus Virchow-Klinikum, Augustenburger Platz 1, 13353 Berlin, Germany. ${ }^{2}$ Clinic of Obstetrics, Charité - Universitätsmedizin Berlin, Corporate Member of Freie Universität Berlin, Humboldt-Universität zu Berlin, and Berlin Institute of Health, Campus Virchow-Klinikum, Berlin, Germany.}

\section{Received: 20 June 2018 Accepted: 14 October 2018}

Published online: 24 October 2018

\section{References}

1. O'Sullivan EP, Avalos G, O'Reilly M, Dennedy MC, Gaffney G, Dunne F, on behalf of the Atlantic DIP collaborators. Atlantic Diabetes in Pregnancy (DIP): the prevalence and outcomes of gestational diabetes mellitus using new diagnostic criteria. Diabetologia. 2011;54:1670-5.

2. Sacks DA, Hadden DR, Maresh M, Deerochanawong C, Dyer AR, Metzger BE, Lowe LP, Coustan DR, Hod M, Oats JJN, Persson B, Trimble ER. Frequency of gestational diabetes mellitus at collaborating centers based on IADPSG Consensus Panel-recommended criteria the hyperglycemia and adverse pregnancy outcome (HAPO) study. Diabetes Care. 2012:35:526-8.

3. Melchior $H$, Kurch-Bek D, Mund M. The prevalence of gestational diabetes a population-based analysis of a nationwide screening program. Dtsch Arztebl Int. 2017;114:412-8.

4. Metzger BE, Buchanan TA, Coustan DR, De Leiva A, Dunger DB, Hadden DR, Hod M, Kitzmiller JL, Kjos SL, Oats JN, Pettitt DJ, Sacks DA, Zoupas C. Summary and recommendations of the Fifth International WorkshopConference on Gestational Diabetes Mellitus. Diabetes Care. 2007:30:S251-60.

5. Brochu-Gaudreau K, Rehfeldt C, Blouin R, Bordignon V, Murphy BD, Palin MF. Adiponectin action from head to toe. Endocrine. 2010;37:11-32.

6. Weyer C, Funahashi T, Tanaka S, Hotta K, Matsuzawa Y, Pratley RE, Tataranni PA. Hypoadiponectinemia in obesity and type 2 diabetes: close association with insulin resistance and hyperinsulinemia. J Clin Endocrinol Metab. 2001;86:1930-5.

7. Fasshauer M, Blüher M, Stumvoll M. Adipokines in gestational diabetes. Lancet Diabetes Endocrinol. 2014;2:488-99.

8. Bao W, Baecker A, Song Y, Kiely M, Liu S, Zhang C. Adipokine levels during the first or early second trimester of pregnancy and subsequent risk of gestational diabetes mellitus: a systematic review. Metabolism. 2015;64:756-64.

9. Hauguel-De Mouzon S, Catalano P. Adiponectin: are measurements clinically useful in pregnancy? Diabetes Care. 2013;36:1434-6.

10. Winzer C, Wagner O, Festa A, Schneider B, Roden M, Bancher-Todesca D, Pacini G, Funahashi T, Kautzky-Willer A. Plasma adiponectin, insulin sensitivity, and subclinical inflammation in women with prior gestational diabetes mellitus. Diabetes Care. 2004;27:1721-7.

11. Retnakaran R, Qi Y, Connelly PW, Sermer M, Hanley AJ, Zinman B. LoW adiponectin concentration during pregnancy predicts postpartum insulin resistance, beta cell dysfunction and fasting glycaemia. Diabetologia. 2010; 53:268-76

12. Catalano PM, Hoegh M, Minium J, Huston-Presley L, Bernard S, Kalhan S, Hauguel-De Mouzon S. Adiponectin in human pregnancy: implications for regulation of glucose and lipid metabolism. Diabetologia. 2006;49:1677-85.

13. Qiao L, Wattez J-S, Lee S, Nguyen A, Schaack J, Hay WW, Shao J. Adiponectin deficiency impairs maternal metabolic adaptation to pregnancy in mice. Diabetes. 2017;66:1126-35.

14. Aye ILMH, Powell TL, Jansson T. Review: adiponectin - the missing link between maternal adiposity, placental transport and fetal growth. Placenta. 2013;34:S40-5.

15. Motoshima H, Wu X, Sinha MK, Hardy VE, Rosato EL, Barbot DJ, Rosato FE, Goldstein BJ. Differential regulation of adiponectin secretion from cultured human omental and subcutaneous adipocytes: effects of insulin and rosiglitazone. J Clin Endocrinol Metab. 2002;87:5662-7.

16. Perrini S, Laviola L, Cignarelli A, Melchiorre M, De Stefano F, Caccioppoli C, Natalicchio A, Orlando MR, Garruti G, De Fazio M, Catalano G, Memeo V, Giorgino R, Giorgino F. Fat depot-related differences in gene expression, adiponectin secretion, and insulin action and signalling in human adipocytes differentiated in vitro from precursor stromal cells. Diabetologia. 2008;51:155-64.
17. Phillips SA, Ciaraldi TP, Oh DK, Savu MK, Henry RR. Adiponectin secretion and response to pioglitazone is depot dependent in cultured human adipose tissue. Am J Physiol Endocrinol Metab. 2008;295:E842-50.

18. Meyer LK, Ciaraldi TP, Henry RR, Wittgrove AC, Phillips SA. Adipose tissue depot and cell size dependency of adiponectin synthesis and secretion in human obesity. Adipocyte. 2013;2:217-26.

19. Ranheim T, Haugen F, Staff AC, Braekke K, Harsem NK, Drevon CA. Adiponectin is reduced in gestational diabetes mellitus in normal weight women. Acta Obstet Gynecol Scand. 2004;83:341-7.

20. Kleiblova P, Dostalova I, Bartlova M, Lacinova Z, Ticha I, Krejci V, Springer D, Kleibl Z, Haluzik M. Expression of adipokines and estrogen receptors in adipose tissue and placenta of patients with gestational diabetes mellitus. Mol Cell Endocrinol. 2010;314:150-6.

21. Liu M, Liu F. Transcriptional and post-translational regulation of adiponectin. Biochem J. 2010:425:41-52.

22. Bouchard L, Hivert MF, Guay SP, St-Pierre J, Perron P, Brisson D. Placental adiponectin gene DNA methylation levels are associated with mothers' blood glucose concentration. Diabetes. 2012;61:1272-80.

23. Kim AY, Park YJ, Pan X, Shin KC, Kwak S-H, Bassas AF, Sallam RM, Park KS, Alfadda A a, Xu A, Kim JB. Obesity-induced DNA hypermethylation of the adiponectin gene mediates insulin resistance. Nat Commun. 2015:6:7585.

24. Jones PA. Functions of DNA methylation: islands, start sites, gene bodies and beyond. Nat Rev Genet. 2012;13:484-92.

25. Plagemann A. Maternal diabetes and perinatal programming. Early Hum Dev. 2011:87:743-7.

26. Retnakaran R, Hanley AJG, Raif N, Connelly PW, Sermer M, Zinman B. Reduced adiponectin concentration in women with gestational diabetes: a potential factor in progression to type 2 diabetes. Diabetes Care. 2004;27:799-800.

27. Sivan E, Mazaki-Tovi S, Pariente C, Efraty Y, Schiff E, Hemi R, Kanety H. Adiponectin in human cord blood: relation to fetal birth weight and gender. J Clin Endocrinol Metab. 2003;88:5656-60.

28. Ballesteros M, Simon I, Ceperuelo-Mallafre V, Miralles RM, Albaiges G, Tinahones F, Megia A. Maternal and cord blood adiponectin multimeric forms in gestational diabetes mellitus: a prospective analysis. Diabetes Care. 2011;34:2418-23.

29. Mantzoros CS, Rifas-Shiman SL, Williams CJ, Fargnoli JL, Kelesidis T, Gillman MW. Cord blood leptin and adiponectin as predictors of adiposity in children at 3 years of age: a prospective cohort study. Pediatrics. 2009;123: 682-9.

30. Dörner $\mathrm{G}$, Plagemann A. Perinatal hyperinsulinism as possible predisposing factor for diabetes mellitus, obesity and enhanced cardiovascular risk in later life. Horm Metab Res. 1994;26:213-21.

31. El HN, Pliushch $G$, Schneider E, Dittrich M, Müller T, Korenkov M, Aretz M, Zechner $U$, Lehnen $\mathrm{H}$, Haaf T. Metabolic programming of MEST DNA methylation by intrauterine exposure to gestational diabetes mellitus. Diabetes. 2013;62:1320-8.

32. Finer $S$, Mathews $C$, Lowe $R$, Smart M, Hillman S, Foo L, Sinha A, Williams D, Rakyan VK, Hitman GA. Maternal gestational diabetes is associated with genome-wide DNA methylation variation in placenta and cord blood of exposed offspring. Hum Mol Genet. 2015;24:3021-9.

33. Haertle L, El Hajj N, Dittrich M, Müller T, Nanda I, Lehnen H, Haaf T. Epigenetic signatures of gestational diabetes mellitus on cord blood methylation. Clin Epigenetics. 2017:9:28.

34. Houshmand-Oeregaard A, Hansen NS, Hjort L, Kelstrup L, Broholm C, Mathiesen ER, Clausen TD, Damm P, Vaag A. Differential adipokine DNA methylation and gene expression in subcutaneous adipose tissue from adult offspring of women with diabetes in pregnancy. Clin Epigenetics. 2017:9:37.

35. Corbetta S, Bulfamante G, Cortelazzi D, Barresi V, Cetin I, Mantovani G Bondioni S, Beck-Peccoz P, Spada A. Adiponectin expression in human fetal tissues during mid- and late gestation. J Clin Endocrinol Metab. 2005;90: 2397-402.

36. Ott R, Stupin JH, Loui A, Eilers E, Melchior K, Rancourt RC, Schellong K, Ziska T, Dudenhausen JW, Henrich W, Plagemann A. Maternal overweight is not an independent risk factor for increased birth weight, leptin and insulin in newborns of gestational diabetic women: observations from the prospective 'EaCH' cohort study. BMC Pregnancy Childbirth. 2018;18:250.

37. Deutsche Gesellschaft für Gynäkologie und Geburtshilfe. Diabetes und Schwangerschaft [Internet], 2008. Available from: https://www.dggg.de/ fileadmin/documents/leitlinien/archiviert/beteiligt/057023 Diabetes und Schwangerschaft/057023_2008.pdf. Accessed 12 June 2018. 
38. Kleinwechter H. Gestations diabetes mellitus (GDM). Dtsch Med Wochenschr. 2012;137:999-1002.

39. Matthews DR, Hosker JR, Rudenski AS, Naylor BA, Treacher DF, Turner RC. Homeostasis model assessment: insulin resistance and $\beta$-cell function from fasting plasma glucose and insulin concentrations in man. Diabetologia. 1985;28:412-9

40. Neville MJ, Collins JM, Gloyn AL, McCarthy MI, Karpe F. Comprehensive human adipose tissue mRNA and microRNA endogenous control selection for quantitative real-time-PCR normalization. Obesity. 2011;19:888-92.

41. Iwaki M, Matsuda M, Maeda N, Funahashi T, Matsuzawa Y, Makishima M, Shimomura I. Induction of adiponectin, a fat-derived antidiabetic and antiatherogenic factor, by nuclear receptors. Diabetes. 2003;52:1655-63.

42. Kita A, Yamasaki H, Kuwahara H, Moriuchi A, Fukushima K, Kobayashi M, Fukushima T, Takahashi R, Abiru N, Uotani S, Kawasaki E, Eguchi K. Identification of the promoter region required for human adiponectin gene transcription: association with CCAAT/enhancer binding protein- $\beta$ and tumor necrosis factor-a. Biochem Biophys Res Commun. 2005;331:484-90.

43. Ikeda K, Maegawa H, Ugi S, Tao Y, Nishio Y, Tsukada S, Maeda S, Kashiwagi A. Transcription factor activating enhancer-binding protein-2beta: a negative regulator of adiponectin gene expression. J Biol Chem. 2006;281: 31245-53.

44. Qiao L, Shao J. SIRT1 regulates adiponectin gene expression through Foxo1C/enhancer-binding protein a transcriptional complex. J Biol Chem. 2006; 281:39915-24.

45. Rancourt RC, Schellong K, Ott R, Bogatyrev S, Tzschentke B, Plagemann A. Acquired alterations of hypothalamic gene expression of insulin and leptin receptors and glucose transporters in prenatally high-glucose exposed three-week old chickens do not coincide with aberrant promoter DNA methylation. PLoS One. 2015;10:e0119213.

Ready to submit your research? Choose BMC and benefit from:

- fast, convenient online submission

- thorough peer review by experienced researchers in your field

- rapid publication on acceptance

- support for research data, including large and complex data types

- gold Open Access which fosters wider collaboration and increased citations

- maximum visibility for your research: over $100 \mathrm{M}$ website views per year

At $\mathrm{BMC}$, research is always in progress.

Learn more biomedcentral.com/submissions 